\title{
The Struvite Precipitation Index: A Practical Framework for Predicting Struvite Supersaturation in Water and
} Wastewater

\author{
Nathaniel J. Barnes, Alan R. Bowers and Matthew P. Madolora \\ Department of Civil and Environmental Engineering, Vanderbilt University, Nashville, TN 37235, USA
}

\begin{abstract}
In wastewater facilities, struvite $\left(\mathrm{MgNH}_{4} \mathrm{PO}_{4} \cdot 6 \mathrm{H}_{2} \mathrm{O}\right)$ precipitation and subsequent accumulation within sludge processing can be an expensive nuisance or a pathway to orthophosphate reclamation and beneficial reuse. Predictive solubility models developed in the past have been computationally intensive, highly conservative, and have employed uncertain equilibrium constants for the evaluation of solution saturation. The StrPI (Struvite Precipitation Index) developed in this study is a new, computationally light framework for predicting struvite precipitation based on saturation $\mathrm{pH}$. The model permits process-specific calibration (i.e. StrPI plus a correction $\mathrm{pH}$ ) to deal with the highly variable characteristics of wastewater streams and to eliminate the $\mathrm{pH}$-independent overprediction inherent in existing solubility models. Verification of this model was performed across a range of waste compositions, ionic strengths, and root-mean-square velocity gradients using data from both synthetic laboratory experiments and field tests. The StrPI framework was found to be an effective and uncomplicated predictor of struvite precipitation in both environments.
\end{abstract}

Key words: Struvite precipitation, scaling, recovery, equilibrium modeling, wastewater.

\section{Introduction}

Struvite $\left(\mathrm{MgNH}_{4} \mathrm{PO}_{4} \cdot 6 \mathrm{H}_{2} \mathrm{O}\right)$ is one of the most prevalent and expensive nuisance precipitates within digestion and postdigestion processes in municipal wastewater treatment. Crystals will readily form on pipes, mixers, and submerged equipment, often costing plants hundreds of thousands of dollars per year in replacement parts and maintenance costs [1-4]. Conversely, recent technologies such as the Ostara ${ }^{\mathrm{TM}}$ and AirPrex ${ }^{\circledR}$ processes have been developed to intentionally precipitate struvite for phosphate and nitrogen recovery as well as a means to produce a high-value, slow-release fertilizer [5, 6]. In both cases, highly variable concentrations and uncertain equilibrium parameters make modeling struvite precipitation an academically and computationally rigorous endeavor, as was explored in Barnes and

Corresponding author: Nathaniel J. Barnes, M.S., PhD Candidate, main research fields: water and wastewater treatment/computer modeling.
Bowers [7]. While moderately effective at predicting precipitation within a range of uncertainty, existing models are highly conservative. As shown in Barnes and Bowers [7], this conservatism often underestimates the $\mathrm{pH}$ of precipitation by more than an order of magnitude, with the result that operators waste resources in an effort to keep $\mathrm{pH}$, magnesium, phosphate, or ammonia at unnecessarily low levels.

In most municipal wastewater plants, day-to-day processes are monitored and controlled by operators on site. These operators are expected to change plant operating parameters to react to variable conditions within the processes, be it increasing/decreasing additive doses, mixer speeds, flow rates, etc. While often highly skilled in their field, plant operators are not expected to have the necessary chemistry and engineering background to execute complex precipitation models such as Monte Carlo simulations to consider uncertainties.

As wastewater stream composition often fluctuates-sometimes rapidly—operators need a 
timely way to predict struvite precipitation. Such a method should be readily translated into adjustments of operating parameters such as $\mathrm{pH}$ and alkalinity, both of which are easily controllable, similar to the Langelier Saturation Index for calcium carbonate [8].

This study proposes and evaluates a struvite precipitation metric, the StrPI (Struvite Precipitation Index), to evaluate the actual $\mathrm{pH}$ of struvite saturation. In its simplest form, this proposed metric is defined as:

$$
\text { StrPI }=p H-p H^{*}
$$

where $\mathrm{pH}$ is the current solution $\mathrm{pH}$ and $\mathrm{pH}^{*}$ is the $\mathrm{pH}$ of struvite saturation. Then, StrPI $>0$ implies supersaturation, $<0$ implies undersaturation (struvite does not precipitate), and 0 implies struvite is at equilibrium.

\section{Uncertainty}

As discussed in depth in Barnes and Bowers [7], the three primary sources of model uncertainty—variable wastewater composition, measurement errors, and disagreement between published equilibrium parameters - have a marked effect on the certainty and predictive bounds of equilibrium models. Concentrations measured from individual grab samples are commonly used in predictive wastewater models [1, 9], as is common in academic analyses. However, operational predictions of struvite precipitation require a site-specific understanding of the variability of solution $\mathrm{pH}$ and concentrations of magnesium, orthophosphate, and ammonium.

In Barnes and Bowers [7], an equilibrium model that accounted for known uncertainty and measured waste-stream variability was found to be effective, though slightly conservative, in predicting struvite precipitation onto metal coupons placed within a conventional centrate nitrification basin. This method, while valuable, requires a level of plant-specific statistical nuance and computational analysis that would be untenable in normal day-to-day operations. Models that rely on empirical calibration and grab-sample data may be less comprehensive, but they allow rapid, informed analysis to be readily applied to active treatment facilities. The struvite precipitation index was developed to be robust enough to maintain predictive power across variable waste streams, but also simple enough to be used in day-to-day operations.

\section{Precipitation Potential}

Precipitation of struvite is the result of a difference in the chemical potential of the salt in a supersaturated solution, $\mu_{\mathrm{s}}$, and the chemical potential of the salt at equilibrium, $\mu_{\infty}$. This difference, $\Delta \mu$, can be given as:

$$
\begin{aligned}
\Delta \mu= & \mu_{\infty}-\mu_{s} \\
= & {\left[\mu_{\infty}^{0}+k T \ln \left(\alpha_{M g^{2+}} \cdot \alpha_{N H_{4}^{+}} \cdot \alpha_{P O_{4}^{3-}}\right)_{\infty}^{1 / 3}\right] } \\
& -\left[\mu_{s}^{0}+k T \ln \left(\alpha_{M^{2+}} \cdot \alpha_{N H_{4}^{+}} \cdot \alpha_{P O_{4}^{3-}}\right)_{s}^{1 / 3}\right]
\end{aligned}
$$

where $k$ is the Boltzmann constant, $T$ is absolute temperature, and $\alpha_{i}$ is the ion fraction of each component [10]. More specifically:

$$
\alpha_{i}=\frac{\text { free ion concentration }}{\text { total dissolved species concentration }}
$$

Assuming that the standard state chemical potentials are equal, or $\mu_{\infty}^{0}=\mu_{s}^{0}$, then

$$
\Delta \mu=k T \ln \left[\frac{\left(\alpha_{\mathrm{Mg}^{2+}} \cdot \alpha_{N_{4}^{+}} \cdot \alpha_{P O_{4}^{3-}}\right)_{\infty}^{1 / 3}}{\left(\alpha_{M^{2+}} \cdot \alpha_{N H_{4}^{+}} \cdot \alpha_{P O_{4}^{3-}}\right)_{s}^{1 / 3}}\right]=-\frac{k T}{3} \ln (\Omega)
$$

Where $\Omega$ is the supersaturation ratio as developed by Bouropoulos and Koutsoukos [10]:

$$
\Omega=\frac{M g_{T} \cdot N_{T} \cdot P_{T}}{K_{s p_{\text {cond }}}}
$$

where $M g_{T}, N p$ and $P_{T}$ are total dissolved magnesium, ammonia (as N), and orthophosphate (as P) as molar concentrations, respectively, and $\alpha_{\mathrm{i}}$ is the ion fraction for each component. $K_{s p}$ is the solubility product for struvite, and $K_{\text {spcond }}$ is the $\mathrm{pH}$-conditional struvite solubility product, given by Ref. [7]:

$$
K_{s p_{\text {cond }}}=\frac{K_{s p}}{\alpha_{M g^{2+}} \cdot \alpha_{N H_{4}^{+}} \cdot \alpha_{P O_{4}^{3-}}}
$$

Following the theory,

$$
\begin{aligned}
& \Omega>1 \Rightarrow \text { supersaturation } \\
& \Omega<1 \Rightarrow \text { undersaturation }
\end{aligned}
$$


Disregarding any limiting kinetics, a supersaturated solution (i.e. $\Omega>1$ ) implies that precipitation will occur. This $\Omega$ factor is the method by which the StrPI is calculated in this study. Note that $\Omega$ is simply a diagnostic ratio and carries no inherent probabilistic information. Expectations attributed to $\Omega$ must be derived empirically on a case-by-case basis due to dissimilarities between wastewater streams and kinetic inconsistencies between processes.

When evaluating struvite precipitation using $\Omega$ calculations, plants may determine and maintain a buffer zone (e.g. keep $\Omega$ below 0.5 rather than 1.0 to eliminate precipitation). However, this correction does not scale with solution $\mathrm{pH}$ and cannot be applied consistently across variable waste streams. The introduction of a $\mathrm{pH}$-based struvite precipitation index, a parameter more easily calculated and conceptualized than $\Omega$, will simplify plant operations. Further, $\mathrm{pH}$ is usually the only parameter that is readily within operator control and thus is a superior unit for model predictions (and calibrations) - as exemplified by the industrywide ubiquity of the Langelier Saturation Index for calculating calcium carbonate saturation [8].

\section{Struvite Equilibrium Chemistry}

Struvite precipitation occurs in solutions where available magnesium, ammonium, and phosphate ions exceed the struvite solubility limit at a given $\mathrm{pH}$, or:

$$
\begin{array}{r}
\mathrm{Mg}^{2+}+\mathrm{NH}_{4}^{+}+\mathrm{PO}_{4}^{3-}+6 \mathrm{H}_{2} \mathrm{O} \\
\Leftrightarrow \mathrm{MgNH}_{4} \mathrm{PO}_{4} \cdot 6 \mathrm{H}_{2} \mathrm{O}
\end{array}
$$

Several studies have investigated strutive solubility at equilibrium, and all generally agree on the form of the struvite solubility product $[1,7,9,11-13]$ :

$$
K_{s p}=\left[M g_{T}\right]\left[N_{T}\right]\left[P_{T}\right]\left(\alpha_{M g^{2+}}\right) \cdot\left(\alpha_{N H_{4}^{+}}\right) \cdot\left(\alpha_{P O_{4}^{3-}}\right)
$$

where $K_{s p}$ is the struvite solubility product and $K_{s p c o n d}$ is the $\mathrm{pH}$-conditional solubility product. For ammonium, orthophosphate, and magnesium, the ionization fractions are described as a function of $\mathrm{pH}$ as follows:

$$
\alpha_{N H_{4}^{+}}=\frac{\left[H^{+}\right]}{\left[H^{+}\right]+K_{a_{1} N}}
$$

$$
\alpha_{P O_{4}^{3-}}=\frac{P O_{4}^{-3}}{P_{f}}=\frac{K_{a_{1} P} \cdot K_{a_{2} P} \cdot K_{a_{3} P}}{\left[H^{+}\right]^{3}+\left(K_{a_{1} P} \cdot\left[H^{+}\right]^{2}\right)+\left(K_{a_{1} P} P K_{a_{2} P} \cdot\left[H^{+}\right]\right)+\left(K_{a_{1} P} \cdot K_{a_{2} P} \cdot K_{a_{3} P}\right)}
$$

$$
\alpha_{M g^{2+}}=\frac{M g^{2+}}{M g_{f}}=\frac{1}{1+K_{1 M g} \cdot\left[\mathrm{OH}^{-}\right]^{+}}
$$

The total dissolved species concentrations $\left(M g_{T}, N_{T}\right.$ and $P_{T}$ ) are:

$$
\begin{gathered}
M g_{T}=M g_{f}+M g P O_{4}^{-}+M g H P O_{4}+M_{g} H_{2} P_{4}^{+} ; \\
N_{T}=N_{3}+\mathrm{NH}_{4}^{+}
\end{gathered}
$$

and,

$$
P_{T}=P_{f}+M_{g P O}^{-}+M_{g} \mathrm{HPO}_{4}^{0}+\mathrm{MgH}_{2} \mathrm{PO}_{4}^{+} \text {; }
$$

which includes:

$$
\begin{gathered}
\mathrm{Mg}_{f}=\mathrm{Mg}^{2+}+\mathrm{MgOH}^{+}+\mathrm{Mg}(\mathrm{OH})_{2}+\mathrm{Mg}(\mathrm{OH})_{3}^{-} \\
P_{f}=\mathrm{H}_{3} \mathrm{PO}_{4}+\mathrm{H}_{2} \mathrm{PO}_{4}^{-}+\mathrm{HPO}_{4}^{2-}+\mathrm{PO}_{4}^{3-}
\end{gathered}
$$

where $M_{g f}$ and $P_{f}$ represent the free magnesium and orthophosphate species, respectively, and $K_{s p}, K_{-}\{a 1 P\}$, $K_{a 2 P}, K_{a 3 P}, K_{a i N}, K_{l M g}, K_{M g P}, K_{M g H P}$ and $K_{M g H 2 P}$ are experimentally derived equilibrium constants reported in the literature.

These ionization fractions are highly $\mathrm{pH}$-dependent. Over the operating range of a typical wastewater treatment plant, from $\mathrm{pH} 6.0$ to 8.5 , struvite solubility decreases significantly as $\mathrm{pH}$ increases. In addition to full reactor supersaturation, struvite may precipitate in localized areas of a treatment process. This may occur around caustic discharge tubes or due to localized $\mathrm{pH}$ increases from $\mathrm{CO}_{2}$ volatilization in low-pressure zones around venturis, pipe bends, and mixing blades. The StrPI may be uniquely useful in mitigating precipitation in these zones if they are characterized individually, as operators can check the $\mathrm{pH}$ of their processes against a set of localized $\mathrm{pH}$ constraints.

In highly saline water (ionic strength $>1.0 \mathrm{M}$ ), Eq. (12) may not be representative of field conditions as chloride/magnesium complexes such as $\mathrm{MgCl}^{+}$may form. In typical wastewater, however, where $\left[\mathrm{Cl}^{-}\right] \leq$ $0.5 \mathrm{M}$ and $\left[\mathrm{Mg}^{2+}\right] \leq 0.1 \mathrm{M}$, these complexes would comprise less than 2 percent of total magnesium and may subsequently be disregarded as negligible. Where 
magnesium and chloride concentrations are high, $\mathrm{MgCl}^{+}$can form, and struvite may precipitate more sparingly than predicted.

\subsection{Equilibrium Constants}

In addition to the struvite equilibrium constant, $K_{s p}$, precipitation is controlled by eight equilibrium equations that together define the speciation of the three principal constituents, $\mathrm{PO}_{4}{ }^{3-}, \mathrm{NH}_{4}{ }^{+}$and $\mathrm{Mg}^{2+}$. These eight equilibrium constants are given by:

$$
\begin{gathered}
K_{a_{1} P}=\frac{\left[\mathrm{H}^{+}\right]\left[\mathrm{H}_{2} \mathrm{PO}_{4}^{-}\right]}{\left[\mathrm{H}_{3} \mathrm{PO}_{4}\right]} \\
K_{a_{2} P}=\frac{\left[\mathrm{H}^{+}\right]\left[\mathrm{HPO}_{4}^{2-}\right]}{\left[\mathrm{H}_{2} \mathrm{PO}_{4}^{-}\right]} \\
K_{a_{3} P}=\frac{\left[\mathrm{H}^{+}\right]\left[\mathrm{PO}_{4}^{3-}\right]}{\left[\mathrm{HPO}_{4}^{2-}\right]} \\
K_{a_{1} N}=\frac{\left[\mathrm{H}^{+}\right]\left[\mathrm{NH}_{3}\right]}{\left[\mathrm{NH}_{4}^{+}\right]} \\
K_{1 M g}=\frac{\left[\mathrm{Mg}^{2+}\right]\left[\mathrm{OH}^{-}\right]}{\left[\mathrm{MgOH}^{+}\right]} \\
K_{M g P}=\frac{\left[\mathrm{Mg}^{2+}\right]\left[\mathrm{PO}_{4}^{3-}\right]}{\left[\mathrm{MgPO}_{4}^{-}\right]} \\
K_{\mathrm{MgHP}}=\frac{\left[\mathrm{Mg}^{2+}\right]\left[\mathrm{HPO}_{4}^{2-}\right]}{\left[\mathrm{MgHPO}_{4}\right]} \\
K_{\mathrm{Mg}_{2} \mathrm{P} P}=\frac{\left[\mathrm{Mg}^{2+}\right]\left[\mathrm{H}_{2} \mathrm{PO}_{4}^{-}\right]}{\left[\mathrm{MgH}_{2} \mathrm{PO}_{4}^{+}\right]}
\end{gathered}
$$

Similar constitutive equations for equilibrium calculations are employed in most published struvite research, but generally use individual, deterministic equilibrium constants [1, 9, 11-13]. Values reported in literature for the nine equilibrium constants vary widely and the effects of these inconsistencies on model uncertainty were found to be nontrivial.

Barnes and Bowers [7] developed a Monte Carlo uncertainty model for struvite, which included associated probability evaluations of plant-specific field data. These results were used to inform the development of the StrPI. However, as variation between waste streams prevents the application of uncertainty calculations from one treatment plant to the next, the struvite precipitation index was developed without the incorporation of the data-driven uncertainty analyses that have characterized former studies. Instead, a generalized method to integrate plant-specific uncertainty into the StrPI is proposed and evaluated.

\subsection{Solubility Product Simplifications}

Once the available fractions of aqueous $\left[\mathrm{Mg}^{2+}\right]$, $\left[\mathrm{NH}_{4}{ }^{+}\right],\left[\mathrm{PO}_{4}{ }^{3-}\right]$ are evaluated at solution $\mathrm{pH}$ and combined with Eq. (9), they calculate the $\mathrm{pH}$-conditional struvite solubility product, $K_{\text {spcond }}$, as described in Eq. (6). Because plant and process-specific uncertainties prohibit the formulation of a general probabilistic solution, the conditional solubility product was calculated as a deterministic value derived from published equilibrium constants. Specifically, as outlined in Barnes and Bowers [7], the published literature constants described in Eqs. (9)-(25) were used as uniformly distributed Monte Carlo inputs, and Eq. (6) was simulated to evaluate all equilibrium constant uncertainties. The median model value from this simulation can be seen as the dashed line in Fig. 1. The $p K_{\text {spcond }}$ is derived from theory and published laboratory data — not field measurements — so it can be standardized for all processes. The quality of this fit can be seen when compared to two prominent struvite studies that evaluated $K_{\text {spcond }}$ in the laboratory $[14,15]$.

A quadratic polynomial, shown in Fig. 1 as a solid line, was fit to the simulated $p K_{\text {spcond. }}$. As this quadratic fit demonstrated exceptional agreement with the calculated $p K_{\text {spcond }}$ and significantly reduces the computational power and theoretical knowledge necessary for StrPI estimations, it was selected as a simplification of the equilibrium model. This pH-dependent quadratic fit is given by:

$$
p K_{s p_{\text {cond }}}=-0.2116 p H^{2}+4.45 p H-14.03
$$

where $p K_{\text {spcond }}$ is the negative base-10 logarithm of $K_{\text {spcond }}$. Coefficients have been truncated for readability and ease of use, and the effects of these truncations were found to be negligible when compared to model precision. The maximum deviation of the quadratic fit 


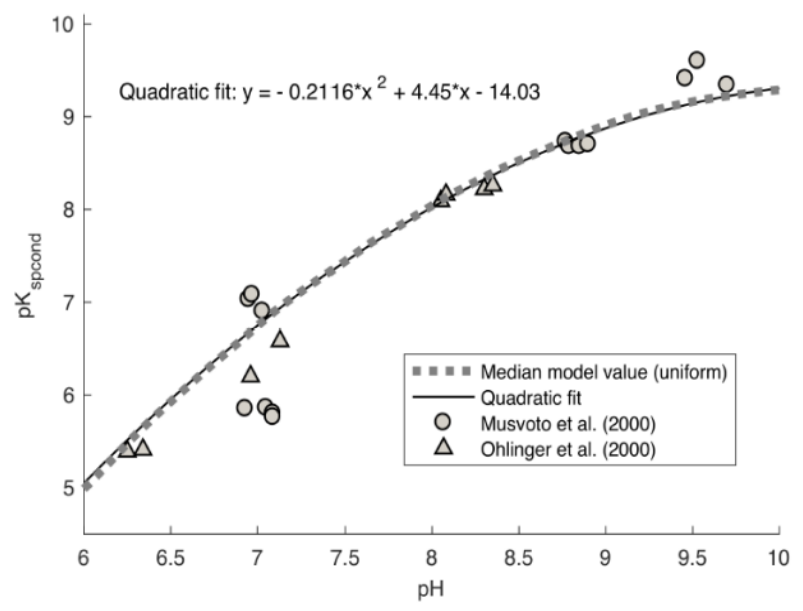

Fig. 1 Median $p K_{\text {spcond }}$ predicted at $25^{\circ} \mathrm{C}$ and $0.1 \mathrm{M}$ ionic strength by the uniform Monte Carlo model described in Barnes and Bowers [7]. Curated datasets of nine published equilibrium parameters $\left(K_{s p}, K_{a 1 P}, K_{a 2 P}, K_{a 3 P}, K_{a 1 N}, K_{1 M g}\right.$, $K_{M g P}, K_{M g H P}$ and $\left.K_{M g H 2 P}\right)$ were used to evaluate Eq. (6). The discrete data points used for comparison were taken from two prominent struvite studies that evaluated $K_{\text {spcond }}$ in the laboratory $[14,15]$.

from the comprehensive model of Barnes and Bowers [7] over $\mathrm{pH} 6.0$ to 8.5 occurs at $\mathrm{pH} 6.0$, and the $p K_{\text {spcond }}$ estimate deviates by less than 1 percent - a more than sufficient fit given other uncertainties. The use of $p K_{\text {spcond }}$ instead of $K_{s p c o n d}$ to develop the fit avoids human and machine computational problems with the use of small decimal coefficients. It also maintains graphical readability.

The model, as described in Eq. (26), was developed for solutions at $25{ }^{\circ} \mathrm{C}$ and $0.1 \mathrm{M}$ ionic strength. The robustness of this simplification over different temperatures and ionic strengths is explored later.

\subsection{Struvite PreciPitation Index}

The $\Omega$ supersaturation ratio, given by Eq. (5), may now be rewritten to incorporate the quadratic approximation of $K_{\text {spcond }}$ :

$$
\Omega=\frac{M g_{T} \cdot N_{T} \cdot P_{T}}{10^{\left(0.2116 p H^{2}-4.450 p H+14.03\right)}}
$$

To formulate a general equation for the StrPI, Eq. (27) must be reorganized to identify the $\mathrm{pH}$ at which $\Omega$ equals exactly 1.0 , defined in this paper as $p H^{*}$. More specifically, $p H^{*}$ is defined by the theoretical point of saturation, or, $\mathrm{Mg}_{T} \cdot \mathrm{N}_{T} \cdot P_{T}=K_{\text {spcond }}$. Without the computational expense of a rigorous $K_{\text {spcond }}$ model, $p H^{*}$ can be easily calculated. First, set $\Omega=1$ and rearrange Eq. (27), or:

$$
0=0.2116 p H^{* 2}-4.450 p H^{*}+14.03-\log _{10}\left(M g_{T} \cdot N_{T} \cdot P_{T}\right)
$$

then employ the quadratic equation and simplify.

$$
p H^{*}=10.52-2.363 \sqrt{7.928+0.8464 \log _{10}\left(M g_{T} \cdot N_{T} \cdot P_{T}\right)}
$$

Combining Eq. (29) with Eq. (1), we can calculate the theoretical, or uncalibrated, struvite precipitation index (StrPI) as:

$$
S t r P I=p H-10.52+2.363 \sqrt{7.928+0.8464 \log _{10}\left(M g_{T} \cdot N_{T} \cdot P_{T}\right)}
$$

where $\mathrm{pH}$ is the current solution $\mathrm{pH}$ and $\mathrm{Mg}_{T}, N_{T}$ and $P_{T}$ are total dissolved magnesium, ammonia (as $\mathrm{N}$ ), and orthophosphate (as $\mathrm{P}$ ) concentrations measured in $\mathrm{mol} / \mathrm{L}$ in a filtered wastewater sample. As with $\mathrm{pH}$, the units of the StrPI are dimensionless.

Eq. (30) is considered uncalibrated as it consistently returns values significantly above zero when precipitation is observed in both the lab and the field. This is simply a translation of the significant-but $\mathrm{pH}$ and concentration-independent - conservative overprediction seen in the underlying $\Omega$ model. This over-prediction may be due to uncertainties in equilibrium constants, impacts of non-ideal temperatures and ionic strengths, the kinetics of precipitation, or a combination of all three. Eq. (30) can be further expanded to incorporate concentrations as $\mathrm{mg} / \mathrm{L}$, the more common units of water and wastewater operations:

$$
S t r P I=p H-10.52+2.363 \sqrt{-3.095+0.8464 \cdot \log _{10}\left(M g_{m g / L} \cdot N_{m g / L} \cdot P_{m g / L}\right)}
$$

where $M g_{m g / L}, N_{m g / L}$ and $P_{m g / L}$, are total dissolved magnesium, ammonia (as $\mathrm{N}$ ), and orthophosphate (as $\mathrm{P}$ ) concentrations measured in $\mathrm{mg} / \mathrm{L}$ in a filtered wastewater sample.

In theory, the calculated StrPI predictions should be evaluated as:

$$
\begin{aligned}
& S t r P I>0 \Rightarrow \text { precipitation } \\
& \text { StrPI }<0 \Rightarrow \text { no precipitation }
\end{aligned}
$$


However, because of the uniform, conservative bias exhibited across all StrPI values (using $C$ as a correction factor between theory and field observations),

$$
\begin{aligned}
& S \operatorname{tr} P I>0+C \Rightarrow \text { precipitation } \\
& \text { StrPI }<0+C \Rightarrow \text { no precipitation }
\end{aligned}
$$

where $C$ is a calibration term applied uniformly to all StrPI values. Preliminary experiments suggested a $C$ value near 1.0, however, lab- and field-based estimations of $C$ (and, thus, $\Omega$ overprediction) are discussed later in terms of a calibrated StrPI. This final corrected model, $\operatorname{Str} P I_{c}$, incorporates the $C$ term and thus may be calibrated for any system (including $T, I$, slow kinetics, or other uncertainty). That this calibration is necessary may be attributable to the kinetic effects that maintain a supersaturated solution, inaccurate equilibrium constants as explored in Barnes and Bowers [7], or even a system of more complex precipitation dynamics. This study does not investigate the source of this uniform correction $(C)$; however, it does seek to quantify and utilize it in the StrPI model.

\section{Methods}

Described in Eq. (30), the StrPI uses a basic polynomial fit to represent the complexities of struvite solubility in a form that can be readily evaluated during regular treatment operations. This research draws its value from its accuracy in predicting struvite precipitation within the range of potential wastewater composition/complexity. However, as shown in field tests performed by Barnes and Bowers [7], the existing models for struvite precipitation (i.e. those derived from the $\Omega$ model from Bouropoulos and Koutsoukos [10]), are highly conservative in practice, i.e., overpredict precipitation.

Preliminary bench-scale experimentation also exhibited this overprediction. This suggested that a full-scale analysis of struvite precipitation across a representative range of potential wastewaters would serve to confirm the veracity of the StrPI framework's representation of the $K_{s p c o n d}$. Such a study would also allow for an analysis of the conservative inaccuracy of existing models and development of a possible correction factor/technique/method.

Full-scale analysis was performed using data from both synthetic laboratory experiments and from field data. Synthetic wastewater allowed the $\operatorname{StrPI} / \operatorname{Str}_{\mathrm{PI}} \mathrm{I}_{c}$ to be tested against a wider range of wastewater compositions in a more controlled environment while field sampling tested the model's efficacy in situ and helped identify any practical limitations.

\subsection{Methods for Synthetic Solutions}

Synthetic aqueous solutions were prepared in a Phipps and Bird PB-900 Series programmable jar tester with square, 2-liter jar-test beakers. Use of these jar testers, an industry standard across American water and wastewater facilities, allow the following experiments to be repeated by utilities using site-specific wastewater compositions. These beakers and associated metal stirrer are designed to create a fully mixed environment with a known, flat, velocity gradient curve. This ensures mixation at predetermined root-mean-squared velocity gradients, $G, \mathrm{~s}^{-1}$.

Room temperature (approximately $25^{\circ} \mathrm{C}$ ) deionized water and various concentrations of ammonia, phosphate, and magnesium were added as ammonium chloride, potassium phosphate, and magnesium chloride, respectively, to create conditions that led to a StrPI near zero at various potential wastewater pHs. Sodium chloride was also added in different concentrations to simulate background ionic strength, and the jar-tester mixing speed was varied to evaluate the impact of the velocity gradient.

Constituents were weighed and added in powder form. This was necessary since constituent solubility at high concentrations made the use of stock solutions less feasible using two-liter beakers. After sodium chloride was added to the deionized water and fully dissolved for background ionic strength, ammonium chloride and potassium phosphate were added, as they 
dissolve more slowly than magnesium chloride. The $\mathrm{pH}$ was then modified to 6.50 using dilute $0.1 \mathrm{~N} \mathrm{NaOH}$. Solutions with higher phosphate alkalinity required the addition of a higher volume of base to achieve the same $\mathrm{pH}$ change. This consequently introduced slightly elevated ionic strengths in highphosphate synthetic solutions compared to other solutions at the same StrPI. This difference was assumed to be negligible, although ionic strength impacts will be addressed later. Once the $\mathrm{pH}$ was set at 6.50 , magnesium chloride was added.

After all constituents dissolved, the $\mathrm{pH}$ was increased by increments of 0.10 units using $0.1 \mathrm{~N}$ $\mathrm{NaOH}$ until precipitation was observed. In cases where precipitation occurs at intermediate $\mathrm{pH}$ values (not multiples of 0.10) ascribed to partial or imprecise $\mathrm{NaOH}$ additions, the $\mathrm{pH}$ of precipitation was recorded to two decimal places.

When added dropwise to a phenolphthalein indicator solution mixed at $G=100 \mathrm{~s}^{-1}$ and a pH of $8.0,0.1 \mathrm{~N}$ $\mathrm{NaOH}$ did not create pinkish plumes. This was not always true for $1 \mathrm{~N} \mathrm{NaOH}$, for which pinkish plumes $(\mathrm{pH}>9)$ were observed. Solutions that did not create pinkish plumes were assumed to be sufficiently mixed without localized areas of elevated $\mathrm{pH}$ (high transient values of $\operatorname{Str} P I>0$ ). This assumption was also evaluated at $G=18 \mathrm{~s}^{-1}$, with similar results.

If the solution was highly supersaturated by a $\mathrm{pH}$ change, struvite usually precipitated heavily within the first minute; however, solutions near saturation occasionally took several minutes to show signs of precipitation, possibly due to nucleation kinetics. Each unprecipitated solution state was therefore allowed to mix for 10 minutes at each $\mathrm{pH}$ step. Filtered samples were taken prior to precipitation to confirm concentrations of added constituents, and after precipitation to confirm an equal reduction in molar concentration of each constituent (as is expected with struvite).

In these experiments where synthetic wastewater was used, struvite precipitation was treated as a binary condition (precipitated/not precipitated), where precipitates were identified visually or by the formation of turbidity using a HACH 2100P portable turbidimeter. Precipitation was further confirmed by a distinct drop in $\mathrm{pH}$ caused by equilibration as phosphate, $\mathrm{PO}_{4}{ }^{3-}$, is removed to form struvite. These results were then verified using ICP-MS on filtered and unfiltered acidified samples to confirm that an equal molar ratio of magnesium and phosphate were removed from the aqueous system.

Dried-sample XRD (X-Ray Powder Diffraction) was conducted to confirm precipitate was entirely struvite. The XRD measurements were performed using a Scintag XGEN-4000 x-ray diffractometer with a $C u K \alpha(\lambda=0.154 \mathrm{~nm})$ radiation source. The molecular structure was then determined by comparing the diffraction patterns to literature data (International Union of Crystallography database). The scans were run from 10-80 degrees in 20 with a 0.1-degree step size and 10 -second dwell time, and all samples were found to be exclusively struvite.

A series of these precipitation experiments was run to examine the effects of constituent concentrations on struvite solubility. Jars were prepared using concentrations ranging from $1 \times 10^{-3}$ to $1 \times 10^{-1} \mathrm{M}$ as $\mathrm{Mg}, \mathrm{P}$ and $\mathrm{N}$. These concentration limits address individual solubility limitations: constituent additions greater than $1 \times 10^{-1} \mathrm{M}$ approach saturation and tend not to fully dissolve. Moreover, concentrations of less than $1 \times 10^{-3} \mathrm{M}$ meant the change in turbidity/concentrations $/ \mathrm{pH}$ could not be evaluated consistently in the jar-tester. These concentration ranges encompass the vast majority of potential scenarios within municipal wastewater facilities. Within this envelope, the constituent concentrations were each evaluated at semi-regular intervals of $1 \times$ $10^{-3} \mathrm{M}, 2.5 \times 10^{-3} \mathrm{M}, 3.5 \times 10^{-3} \mathrm{M}, 5 \times 10^{-3} \mathrm{M}, 8 \times 10^{-3}$ $\mathrm{M}, 1 \times 10^{-2} \mathrm{M}, 2.5 \times 10^{-2} \mathrm{M}, 3.5 \times 10^{-2} \mathrm{M}, 5 \times 10^{-2} \mathrm{M}, 8$ $\times 10^{-2} \mathrm{M}, 1 \times 10^{-1}$. As a result of the nonlinear $\mathrm{pH}$ response of struvite precipitation, the use of regular measurement intervals resulted in clustered StrPI vs. $\mathrm{pH}$ data. These semi-regular intervals were selected to 
allow StrPI to be thoroughly evaluated across the range of typical wastewater concentrations and $\mathrm{pHs}$.

Magnesium was not added above a concentration of $5 \times 10^{-2} \mathrm{M}$ because of concerns about magnesium chloride solubility and the influence of concentrated chloride and magnesium ions on ionic strength. Since $\mathrm{Mg}^{2+}$ is often the limiting reactant for struvite formation in municipal waste, as measured in Barnes and Bowers [7] and Doyle and Parsons [9], this will likely have no effect on the applicability and evaluation of the model.

The three constituents were added in a variety of triplicates to simulate a wide range of waste compositions and to confirm the conclusion of Bouropoulos and Koutsoukos [10] that no particular constituent(s) contributed disproportionally when they were present in more than the 1:1:1 stoichiometric ratio. Both the $S t r P I_{c} / \operatorname{Str} P I$ and the underlying $\Omega$ model of Bouropoulos and Koutsoukos [10] rely on this assumption when solubility is calculated as a function of the product of $[\mathrm{Mg}],[\mathrm{P}]$ and $[\mathrm{N}]$.

Constituent triplicates were added following one of seven templates:

(1) Equal molar concentrations: $[\mathrm{Mg}]=[\mathrm{P}]=[\mathrm{N}]$

(2) $[\mathrm{Mg}] 10 \times$ higher than $[\mathrm{P}]$ and $[\mathrm{N}]:[\mathrm{Mg}]=10 \times[\mathrm{P}]=10 \times[\mathrm{N}]$

(3) $[\mathrm{P}] 10 \times$ higher than $[\mathrm{Mg}]$ and $[\mathrm{N}]:[\mathrm{P}]=10 \times[\mathrm{Mg}]=10 \times[\mathrm{N}]$

(4) $[\mathrm{N}] 10 \times$ higher than $[\mathrm{Mg}]$ and $[\mathrm{P}]:[\mathrm{N}]=10 \times[\mathrm{Mg}]=10 \times[\mathrm{P}]$

(5) $[\mathrm{Mg}] 10 \times$ lower than $[\mathrm{P}]$ and $[\mathrm{N}]:[\mathrm{Mg}]=0.1 \times[\mathrm{P}]=0.1 \times[\mathrm{N}]$

(6) $[\mathrm{P}] 10 \times$ lower than $[\mathrm{Mg}]$ and $[\mathrm{N}]:[\mathrm{P}]=0.1 \times[\mathrm{Mg}]=0.1 \times[\mathrm{N}]$

(7) $[\mathrm{N}] 10 \times$ lower than $[\mathrm{Mg}]$ and $[\mathrm{P}]:[\mathrm{N}]=0.1 \times[\mathrm{Mg}]=0.1 \times[\mathrm{P}]$

This method allows for each constituent to serve as the stoihiometrically limiting or oversupplied molecule in the reaction, maintains order to the data, and evaluates StrPI across a large range of typical wastewater compositions.

The jars were initially mixed at $\mathrm{pH} 6.5$ with a root-mean- square velocity gradient of $100 \mathrm{~s}^{-1}(100$ $\mathrm{rpm}), 44 \mathrm{~s}^{-1}$ (50 rpm), or $18 \mathrm{~s}^{-1}$ (25 rpm), using the Phipps and Bird PB-900 Series shear-rated paddles. Experimentation was limited to the regions between $\mathrm{pH} 6.5$ and 8.5 because these are standard operating ranges for treatment processes that exhibit struvite and, notably, this is the envelope over which struvite constituents remain soluble at concentrations used but are still concentrated enough to accurately measure precipitation by means of turbidity and the associated pH drop.

Individual experiments were run using either 0.01 , or $0.5 \mathrm{M}$ background ionic strength-added as $\mathrm{NaCl}$ - to evaluate the StrPI over a range representative of wastewater.

\subsubsection{Temperature Simplifications}

Solution temperature has the potential to significantly affect the solubility of struvite, as discussed in Barnes and Bowers [7], Aage, et al. [16], Hanhoun, et al. [17], and Bhuiyan, et al. [18]. While published values of struvite solubility product at different temperatures would ideally serve to inform an empirical model such as the StrPI, the uncertainty in equilibrium constants renders analysis difficult [7]. For example, using the dataset for the $p K_{s p}$ of struvite compiled in Barnes and Bowers [7] and comprised of data from IUPAC [19], Hanhoun, et al. [17], and Ohlinger, et al. [1], the temperature variability of the $p K_{s p}$ over the range of 15 to $40{ }^{\circ} \mathrm{C}$ is on the same order of magnitude as the uncertainty derived from inconsistencies in published equilibrium constants at $25^{\circ} \mathrm{C}$. This is best represented in Fig. 2, where literature values for the struvite $p K_{s p}$ evaluated at zero ionic strength are plotted against their associated temperatures.

As is apparent in Fig. 2, beyond a possible linear correlation between temperature and the $p K_{s p}$, conclusions cannot be drawn without more agreement between published solubility constants. Consequently, thermal effects were not included in this study. However, it is assumed that temperature will be appropriately modeled with the $\operatorname{Str} P 1_{c}$.

Research performed by Hanhoun, et al. [17] using a smaller dataset of published $p K_{s p}$ values found that over the temperature range of 15 to $35{ }^{\circ} \mathrm{C}, p K_{s p}$ values ranged from $13.29( \pm 0.02)$ to $13.08( \pm 0.06)$. In a similar study, Bhuiyan, et al. [18] found $p K_{s p}$ values 


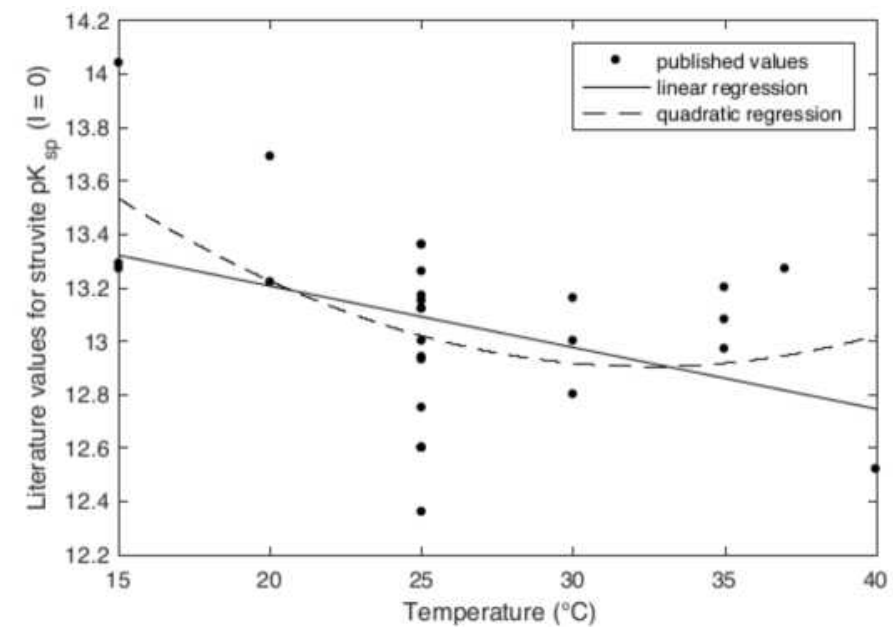

Fig. 2 Literature values for for the $p K_{s p}$ of struvite from IUPAC [19], Hanhoun, et al. [17], and Ohlinger, et al. [1] are plotted against their associated temperatures. The plotted data are taken only from published constants measured in solutions of zero ionic strength as such solutions are the most widely reported by a substantial margin (allowing for a larger dataset). Linear (solid line) and quadratic (dashed line) least-squares regressions had adjusted R-squared values of 0.131 and 0.257 respectively. Higher order polynomial regressions fit with similarly poor results. This degree of uncertainty in published $p K_{s p}$ values precludes deeper insight into temperature functionality.

ranged from $14.04( \pm 0.03)$ to $13.20( \pm 0.03)$ over the same temperature range. These values are highly dissimilar, but both studies generally agree that an increase in temperature over this range results in an increased struvite solubility.

Actual wastewater streams can exhibit seasonal, diurnal and spatial temperature variations; further model calibration may be required when stream temperatures deviate significantly from $25{ }^{\circ} \mathrm{C}$. This is especially true for colder solutions when the aim is to prevent precipitation, as thermal functionality will slightly lower solubility. However, as waste streams generally do not undergo significant temperature changes over short periods of time, consistent model calibration will likely mitigate these effects.

\subsubsection{Impact of Kinetics}

The kinetics of struvite precipitation are difficult to predict and model, especially in solutions near the point of saturation. In identical supersaturated solutions, time to precipitation may differ by minutes, possibly resulting from small errors in measurements or non-homogeneity due to experimental imperfections. Further, the colloidal chemistry of struvite particle formation can be broken into three distinct phases-nucleation, coagulation, and flocculation - each controlled by different wastewater properties and exhibiting highly dissimilar rates of foulant agglomeration [20, 21]. The diagram in Fig. 3 depicts the relative rates of struvite formation/accumulation as well as the pertinent wastewater properties influencing each phase. It is possible that the short-term efficacy of the StrPI equilibrium model will be more affected by the slower nucleation phase (associated with constituent concentrations and $\mathrm{pH}$ ) than the coagulation phase (influenced by critical coagulation concentration and ionic strength) since the slower colloid formation processes inherently take longer to reach equilibrium.

For the sake of specificity, this research did not focus on kinetics, but relied instead on long mixing times and the simplicity of binary precipitation data to reduce its

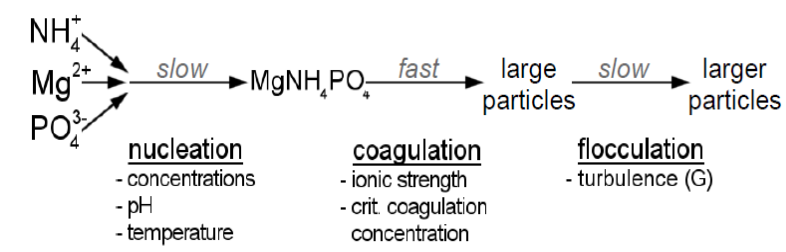

Fig. 3 A schematic outlining the three phases of struvite formation/accumulation and their relative kinetic rates [20, 21]. The impactful wastewater properties are labeled for each phase. 
effects on the data. However, in variable wastewater systems kinetics may cause a cycle of precipitation and dissolution. This may go unnoticed or be impossible to record within a Boolean framework.

Laboratory and field scale experimentation performed in this study and in Barnes and Bowers [7] found that the $\Omega$ model presented in Bouropoulos and Koutsoukos [10] was highly conservative, often predicting precipitation almost a full $\mathrm{pH}$ point before it was observed. Solution kinetics are likely only one of many factors that affect these predictions; nevertheless, the ability to calibrate the StrPI to incorporate kinetic effects is imperative to model flexibility.

\subsection{Methods for Field Experiments}

Considering the variety of conditions present in a wastewater treatment plant [7], laboratory-scale experimentation does not necessarily translate to the field. Before it can be used, the StrPI must be shown to be applicable to field cases. A field test was performed in the centrate nitrification basins $\left(\mathrm{NH}_{4}{ }^{+} \rightarrow \mathrm{NO}_{3}{ }^{-}\right)$of a struvite-burdened metropolitan wastewater treatment facility. Aluminum coupons were placed at eight critical locations around a conventional plug-flow aeration basin, and water samples were taken several times a day at each point. The 415 -meter-long $(1,360 \mathrm{ft})$ basins contained treated centrate from anaerobically digested wastewater sludge, and had an average residence time of approximately 2 days. Concentrations of the main constituents of struvite (generally: $\mathrm{NH}_{4}{ }^{+}>$ $\mathrm{PO}_{3}^{-}>\mathrm{Mg}^{2+}$ ) varied greatly over time due to inconsistency in the centrate source. Struvite formed throughout the basins, but predominately in locations of localized $\mathrm{pH}$ spikes caused by $\mathrm{CO}_{2}$ stripping or caustic addition. The wastewater $\mathrm{pH}$ was initially raised to around 7.0 prior to nitrification to ensure biological activity. The influent also included flow from the main aeration basins (bacterial seed), and a recycle stream from the tail end of the centrate basins (about 1 million gallons per day each).
When struvite crystals precipitated onto the metal coupons over a set period, they were dissolved in acid and the constituents were analyzed using ICP-MS (Inductively Coupled Argon Plasma Mass Spectrometry). An example of a fouled coupon (precipitation present) can be seen in Fig. 4. In all cases, the magnesium-to-calcium ratio exceeded 100:1 and chloride was found to be negligible. More importantly, the $\mathrm{Mg}: \mathrm{P}$ ratio indicated struvite as the major precipitate. To confirm, XRD measurements were performed, and the sample was found to be predominately struvite.

The field experiment was performed for 2 weeks, with eight samples taken daily from the nitrification basin at points near submerged coupons. Measurements of ammonia and phosphate were performed on site using a LaMotte 1,200 colorimeter, with a sensitivity

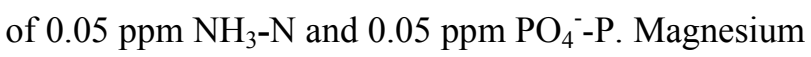
was measured using an ICAP Q ICP-MS in accordance with Bridgewater, et al. [22]. A Fisher Scientific accumet AP85 portable pH meter was used to measure the $\mathrm{pH}$. The temperature was measured as approximately $25{ }^{\circ} \mathrm{C}$ with only minor variability, and the average ionic strength was estimated using Eq. (34) and grab-sample measurements of solution electrical conductivity (EC, in $\mu \mathrm{S} / \mathrm{m})$.

$$
\log I=1.159+1.009 \log E C
$$

valid for $I<0.3 \mathrm{M}[23,24]$.

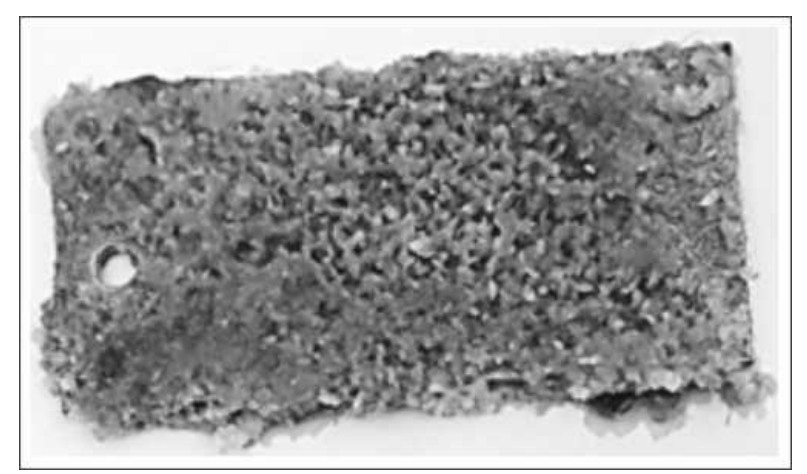

Fig. 4 Coupon fouled with struvite from field experiments. This specific coupon was submerged at a point 325 feet $(99$ meters) along a nitrification basin and removed after two weeks' contact time. 
Conductivity was measured five times over two weeks, with variability of less than 20 percent between samples. Ionic strength was estimated as approximately $0.1 \mathrm{M}( \pm 10 \%)$. The conditions for supersaturation over the two weeks were evaluated by the StrPI model using the coupon precipitation data in conjunction with the $\mathrm{pH}$ and constituent concentration measurements. The rate of struvite crystal redissolution has not been evaluated, but it is likely slower than the rate of precipitation due to layering effects and localized areas of elevated constituent concentrations around solid particles. Consequently, it is likely that the maximum value (or a high percentile, such as the 90th) of measured $\mathrm{pH}$ and constituent concentrations are more useful in long-term fouling predictions than average values.

\section{Laboratory Results}

\subsection{Approximating Measurement Error}

Struvite precipitation in synthetic solutions near saturation is affected by localized kinetics, concentration inhomogeneities, and general measurement errors-all which contribute inescapable uncertainty in any predictive model. However, such a model may also exhibit uncertainty and inaccuracy through the effects of various simplifications and assumptions. Should the model simplification errors fall within the acceptable predictive range, then the effects of the simplification or assumption can be deemed negligible for the purposes of practical application.

Each jar test evaluation of the StrPI framework resulted in a measured $\mathrm{pH}$ of precipitation. Eq. (30) and experiment-specific concentration data were then used to calculate StrPI at the point of precipitation (which was not 0 , as predicted theoretically), denoted as StrPI*. For a calibrated StrPI model, precipitation should occur at $\operatorname{Str} P I_{c}=0$ for all experimental conditions; however, StrPI* includes the conservatism of the $\Omega$ model so the uncalibrated values are much higher - generally nearer to 1.0. The $\operatorname{Str} P I^{*}$ inaccuracies are partitioned into two statistically independent components: measurement errors and model simplification errors. For a set of $S t r P I^{*}$ precipitation data, $S^{*}$, the variance of the set can be written as the sum of the variances of the two components [25], or:

$$
\operatorname{Var}\left(S^{*}\right)=\operatorname{Var}(M E)+\operatorname{Var}(\epsilon)
$$

where $M E$ represents the measurement errors, $\varepsilon$ represents the model errors, and the Var function denotes the variance of its argument. $\operatorname{Var}(M E)$ was estimated by evaluating the difference between the measured StrPI* of duplicate experiments, each sharing identical concentrations of $[\mathrm{Mg}],[\mathrm{P}]$ and $[\mathrm{N}]$ as well as identical background ionic strengths and mixing speeds.

These StrPI* residuals were calculated from a series of 27 duplicate pairs containing a wide range of constituent triplicates and ionic strengths, all at a $G$ of $100 \mathrm{~s}^{-1}$. As duplicate experiments contain the same model error, $\varepsilon$, the variance of the residuals is entirely due to the variance of measurement error. Following Ang and Tang [25], this relationship can be used to estimate $\operatorname{Var}(M E)$ :

$$
\operatorname{Var}(M E) \approx \frac{\operatorname{Var}(R)}{2}
$$

where $R$ is an array of $\operatorname{Str} P I^{*}$ residuals between duplicate experiments.

For the synthetic experiments, $M E$ was found to have a variance of 0.017 , which results in a standard deviation of approximately $0.131 \mathrm{pH}$ units. This is within the range of acceptable model uncertainty, especially as temporal and localized wastewater variability would generally negate the value of a more accurate model. A one-sample Student's $t$-test ( $p=$ 0.05 ) was performed on $R$ and the residuals were found to be approximately normally distributed. The estimated measurement error was subtracted from the right side of Eq. (35) to calculate $\varepsilon$. This facilitates investigations into the effects of ionic strength and root-mean-square velocity gradient simplifications of the StrPI.

\subsection{Ionic Strength Analysis}

Ions added as a byproduct of increasing $\mathrm{pH}$ (by 
adding $\mathrm{NaOH}$ ) or added as ammonium chloride, potassium phosphate, or magnesium chloride, were rendered negligible by the addition of $0.01 \mathrm{M}$ or 0.50 $\mathrm{M} \mathrm{NaCl}$ as swamping ionic strength, $I$. The maximum value of $I(0.50 \mathrm{M})$ was not set to a higher value because of concerns of magnesium chloride interference at more concentrated doses as described in Barnes and Bowers [7]. Nonetheless, both the addition of constituents and the $\mathrm{pH}$ modification during experimentation cause an inherent increase in the ionic strength of the solution. In cases involving precipitation at a relatively low $\mathrm{pH}$ (i.e. well below 7.0) and $0.01 \mathrm{M}$ background $\mathrm{NaCl}$, the necessary elevated constituent levels may overcome the background ionic strength's swamping effect and reach non-background ion concentrations comparable to that supplied by the $\mathrm{NaCl}$.

While ionic strength is an important modeling consideration, in wastewater it can be highly dissimilar between individual plants (magnitude and composition) and between periodic grab samples. Moreover, ionic strength is generally estimated using conductivity measurements - $\mathrm{a}$ method understood to introduce some uncertainty. This research is meant to simplify the prediction of struvite precipitation so that the StrPI can be approximated promptly, and eliminate exhaustive experimentation required to include an ionic strength factor. Nonetheless, the effect of ionic strength variability between experimental runs was assessed.

Preliminary experiments suggested that solution ionic strength has a small to negligible effect on measured $\operatorname{Str}^{*} I^{*}$ over the range of experimental constituent concentrations. This result suggests that ionic strength effects can be assessed by evaluating the model at its boundary conditions. Time-intensive experiments that use a grid of ionic strengths to span the model's expected practical range, as was done with constituent concentrations, can thus be eliminated. This analysis at boundary conditions again collects pairs of "duplicate" solutions $([\mathrm{Mg}],[\mathrm{P}]$ and $[\mathrm{N}]$ ranging from
$1 \times 10^{-3}$ to $1 \times 10^{-1} \mathrm{M}$ ); however, in this case, the background ionic strength of one duplicate is added at $0.01 \mathrm{M}$, while the other is added at $0.50 \mathrm{M}$.

This method does not model the functional effects of ionic strength on StrPI*. Instead, it quantifies the impact of the effect across a range of probable wastewater conditions. As published solubility products suggest that the relationship between $K_{\text {spcond }}$ and ionic strength contains no inflection points over the model range, the use of maximum and minimum values for $I$ should encapsulate the range's full breadth of ionic strength interference on $\operatorname{StrPI}^{*}$ [19].

An analysis of variance on the $\operatorname{Str} P I^{*}$ data using a linear fixed effects model was performed to evaluate the effects of ionic strength, as is discussed later. As the ionic strength was evaluated at only one of two values, the condition of background ionic strength was converted to a binary value $I_{x}$, set at 0 for $I=0.01 \mathrm{M}$ and 1 for $I=0.50 \mathrm{M}$.

\subsection{Root-Mean-Square Velocity Gradient Analysis}

Past field studies have evaluated the range of wastewater turbulence within municipal treatment facilities. These studies reported values in the form of the root-mean-square velocity gradient, $G$, a common measure of mixing intensity generally used to define flocculation. Specifically, Das, et al. [26] ran a comprehensive field study of the effects of the root-mean-square velocity gradient on a full-scale activated sludge wastewater treatment plant that evaluated and expanded upon the conclusions of Parker, et al. [27]. While these papers suggested that ideal flocculation occurs at a $G$ between $20-70 \mathrm{~s}^{-1}, G$ values measured in the aeration basins of 14 full-scale treatment plants were much higher, resulting in a general range of 88-220 $\mathrm{s}^{-1}$ [26]. Additionally, Das, et al. [26] measured the $G$ in mixed liquor transport systems and found that values ranged between 1 and $72 \mathrm{~s}^{-1}$.

The StrPI $I^{*}$ baseline experiments performed in this study were run at 100 revolutions per minute (rpm). From the Phipps and Bird documentation, at room 
temperature this imparts a homogeneous root-mean-square velocity gradient, $G$, of $100 \mathrm{~s}^{-1}$. This value was selected as it allowed for adequate mixing of the added constituents, fit within the range supplied by Das, et al. [26] for aeration basins, and would not create a large vortex.

To examine the specific effects of $G$ on struvite precipitation, the $100 \mathrm{rpm}$ experiments were replicated using $G$ values of $18 \mathrm{~s}^{-1}$ (25 rpm) and $44 \mathrm{~s}^{-1}$ (50 rpm). For the $G=18 \mathrm{~s}^{-1}$ experiment runs, constituents were rapidly mixed at a low $\mathrm{pH}$ to allow for faster dissolution. However, the paddle speed was slowed before the $\mathrm{pH}$ was brought above 6.5 .

The impact of turbulence on precipitation was determined by comparing 34 slowly mixed (25 rpm) solutions to 34 quickly mixed (100 rpm) but otherwise identical solutions-employing the same method as used with ionic strength. The velocity gradient was also treated as a binary value, $G_{x}$, for use in the linear fixed effects model: $100 \mathrm{~s}^{-1}$ was set as $G_{x}=1$ and $18 \mathrm{~s}^{-1}$ was set as $G_{x}=0$.

Unlike the ionic strengths included in $I_{x}$, the selected $G$ values are not meant to encompass the entire range of potential turbulence within a treatment plant. They do, however, represent a significant difference in root-mean-square velocity gradient, and encompass the entire "ideal aeration basin" span of 20-70 s $\mathrm{s}^{-1}$ described in Das, et al. [26] and Parker, et al. [27]. Should the difference between these two mixing rates have no significant effect on StrPI, it is unlikely that values outside this range would differ.

We note that turbulence simulated using synthetic precipitation does not encompass all impacts of mixing rates in the field. Specifically, in an open-air wastewater process, localized areas with high velocity gradients may evolve and release $\mathrm{CO}_{2}$ at faster rates than are occurring in the bulk solution. This can cause small pockets of elevated $\mathrm{pH}$ which inherently exhibit higher StrPI* values than are predicted by bulk-flow $\mathrm{pH}$ measurements. In these cases, the StrPI may be calibrated to the local areas of elevated $\mathrm{pH}$, or a safety factor may be implemented independently of the StrPI equation.

\subsection{Analysis of StrPI Using a Linear Fixed Effects Model}

There are two principal factors of interest: ionic strength and mixing speed. To quantify the impact of these two factors, a standard linear fixed effects model was fit to the data and an associated analysis of variance was carried out [28]:

$$
\text { StrPI* }=a I_{x}+b G_{x}+\text { intercept }
$$

where $\operatorname{Str} P I^{*}$ is the measured StrPI at precipitation; $I_{x}$ is the binary set representing ionic strengths of $I=0.01$ and $I=0.50$ as 1 and 0 , respectively; $G_{x}$ is the binary set representing root-mean-square velocity gradients of $100 \mathrm{~s}^{-1}$ and $18 \mathrm{~s}^{-1}$ as 1 and 0 , respectively; and $a, b$, and intercept represent fitted constants. As the binary $I_{x}$ and $G_{x}$ variables span the range of expected ionic strength and turbulence values, respectively, $a$ and $b$ represent the magnitude of each factor's impact on the measured StrPI* (e.g. a larger $a$ value means a larger expected difference between the StrPI* in solutions of $0.01 \mathrm{M}$ vs. $0.50 \mathrm{M}$ ionic strength). The intercept coefficient represents the magnitude of the uniform bias in the uncalibrated StrPI model that causes precipitation to not occur at $\operatorname{Str} P I^{*}=0$ (not a function of ionic strength and mixing speed).

A regression algorithm was used to minimize the sum of the squares of the errors for all $\operatorname{StrPI}^{*}$ data with initial conditions included within $I_{x}$ and $G_{x}$ (77 runs). The results of this fit can be seen in Table 1 .

\subsubsection{Estimation of Model Uncertainty}

The RMSE (Root Mean Squared Error) was evaluated for the 77 experimental runs. This value, 0.127 , serves as an approximation of the standard deviation of the regression errors and is comparable to 0.131 , the approximate standard deviation of measurement error calculated using Eq. (36). The similarity between these two values suggests that the fixed effects model sufficiently captured the model error, $\varepsilon$. This absence of 
Table 1 Regression results for linear fixed effects model of measured $\mathrm{StrPI}^{*}$ values described in Eq. (37). The p-value is calculated for a null-hypothesis where the coefficient is equal to zero. Note: coefficients $a$ and $b$ apply to the binary $I_{x}$ and $G_{x}$ data, not $I$ or $G$, and thus should not be used to estimate functionality. Instead, the estimates simply compare the change in $\operatorname{StrPI}^{*}$ when $I$ or $G$ vary between their max and min values.

\begin{tabular}{|c|c|c|c|c|}
\hline Coefficient & Estimate & Std error & $\mathrm{t}-\mathrm{Stat}$ & $p$-Value \\
\hline $\mathrm{a}$ & 0.0453 & 0.0408 & 1.11 & 0.271 \\
\hline $\mathrm{b}$ & -0.0182 & 0.0384 & -0.473 & 0.637 \\
\hline Intercept & 1.16 & 0.0340 & 34.1 & $5.14 \times 10^{-47}$ \\
\hline Num. Obs. & \multicolumn{2}{|c|}{ MSE } & \multicolumn{2}{|c|}{ RMSE } \\
\hline 77 & \multicolumn{2}{|c|}{0.0162} & \multicolumn{2}{|c|}{0.127} \\
\hline
\end{tabular}

unexplained error also implies that using the product of $[\mathrm{Mg}],[\mathrm{P}]$ and $[\mathrm{N}]$ to model saturation, as suggested by Bouropoulos and Koutsoukos [10], is robust when evaluated at different stoichiometric ratios.

\subsubsection{Impacts of Ionic Strength and Velocity} Gradient

The least-squares estimates for the $I_{x}$ and $G_{x}$ coefficients, $a$ and $b$, were both small. Moreover, the estimates had a standard error of similar magnitude. The associated $p$-values also failed to reject the null-hypotheses of both $a=0$ and $b=0$ (using a level of significance, $\alpha$, of 0.05 ), meaning the coefficients are statistically indistinguishable from zero. This suggests the difference in saturation points between solutions with 0.01 and $0.50 \mathrm{M}$ background ionic strength is insignificant (accounting for an estimated 0.045 unit shift of $\mathrm{pH}^{*}$ ). The same conclusion can be drawn about saturation between solutions where $G=$ $100 \mathrm{~s}^{-1}$ and $G=18 \mathrm{~s}^{-1}$. It must be noted, "statistically insignificant" is not equivalent to "has no effect". It is possible that ionic strength and mixing speed have slight effects on struvite precipitation over their expected ranges, but these impacts are swamped by measurement errors during statistical analysis. Nonetheless, $I$ and $G$ are unlikely to affect practical applications.

A second set of mixing speed duplicate residuals (44 vs. $100 \mathrm{~s}^{-1}$ ) was used in the fixed effects model to confirm the viability of root-mean-square velocity gradient assumptions across the $18 \mathrm{~s}^{-1}$ to $100 \mathrm{~s}^{-1}$ envelope. This second set compared 21 moderately turbulent solutions (44 $\left.\mathrm{s}^{-1}, G_{x}=0\right)$ to 21 highly turbulent ones $\left(100 \mathrm{~s}^{-1}, G_{x}=1\right)$. This analysis also failed to reject the null hypothesis, which supports the conclusions of the first $G_{x}$ set. In conclusion, the effect of ionic strength and mixing speed over the model's applicable range is statistically indistinguishable from zero, and $I$ and $G$ terms can be justifiably excluded from the StrPI model.

\subsubsection{Estimating Bias in the Uncalibrated Model}

In addition to $a$ and $b$, the fixed effects analysis outlined in Table 1 estimated the y-intercept of the linearized $\operatorname{Str} P I^{*}$ model. Calculated as 1.16, intercept represents the magnitude of the uniform overprediction of an uncalibrated model. This bias can be observed in Fig. 5, where the dataset of $\operatorname{StrPI}^{*}$ values included in the fixed effects model is plotted against solution $\mathrm{pH}$ at precipitation, $p H^{*}$. Note, the mean $\operatorname{Str} I^{*}$ is approximately 1.16 , whereas an ideal calibrated prediction, StrPI*, should have a mean near zero.

The bias in Fig. 5 highlights the need for model calibration. It also suggests an estimate of the StrPI calibration value, $C$, described in Eq. (33). The value of intercept from Table 1 serves as a good initial guess for $C$; however, it does not take into account the site-specific requirements of the model, i.e., setting the calibration to eliminate either false negatives or false positives. Specifically, when trying to prevent struvite scaling, an ideal calibration would see precipitation occur at or above the point where $\operatorname{Str} I_{c}=0$. Likewise, when trying to facilitate struvite precipitation, the selected $C$ should be higher than 1.16 to allow precipitation to occur before $\operatorname{StrPI}_{c}=0$, with the exact value set in consideration of the necessary level of certainty.

Fig. 6 contains the normal probability plot of all measured $\mathrm{StrPI}^{*}$ values generated from the synthetic precipitation experiments. It indicates that StrPI prediction uncertainty at known initial conditions is approximately normally distributed. 


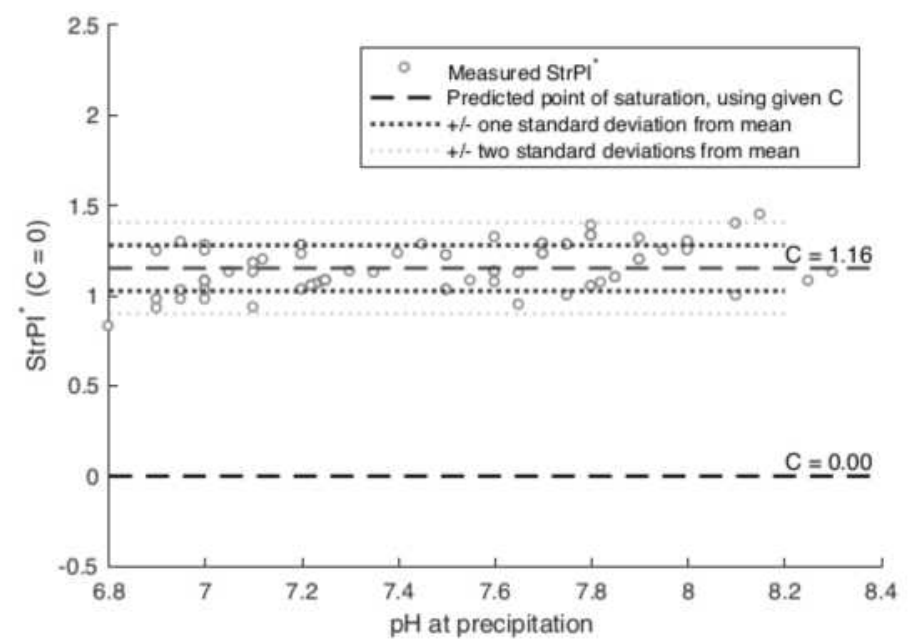

Fig. 5 The calculated $S t r P I^{*}$ vs. actual measured $\mathrm{pH}$ of precipitation for all synthetic struvite precipitation experiments included in the fixed effects model (77 points). The estimated bias, intercept $=\mathbf{1 . 1 6}$, and associated error bars were drawn from the synthetic experiments. Note, many of the data points are coincident or stratified as a result of identical duplicate pairs and the 0.10 unit resolution of $\mathrm{pH}$ measurements.

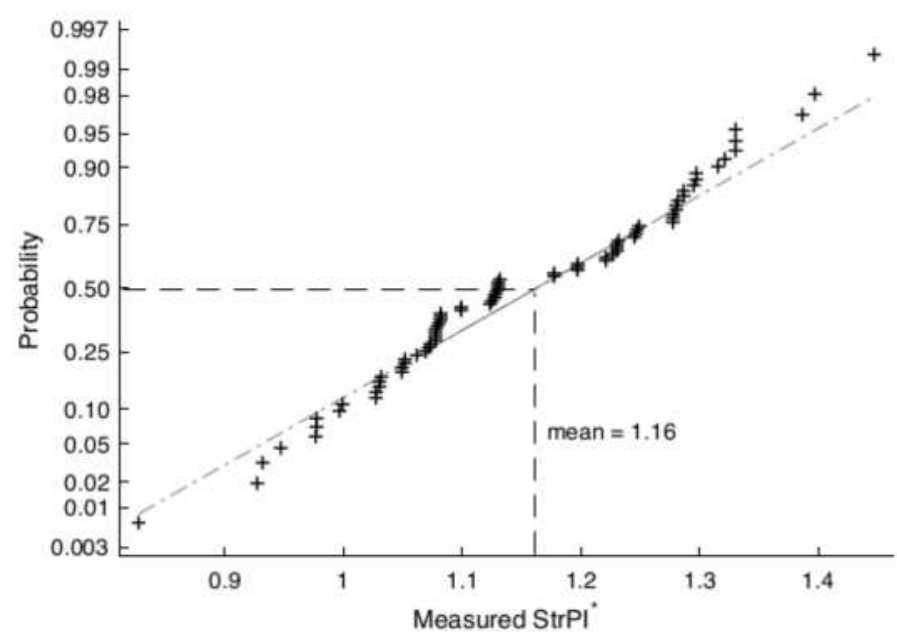

Fig. 6 The normal probability plot of all measured $S t r P I^{*}$ values generated from the synthetic precipitation experiments. The assumption of normality was supported by a one-sample Student's $t$-test $(\alpha=0.05)$.

Using the linear effects model outlined in Table 1, the uncertainty of the StrPI model was estimated to have a standard deviation of $0.127 \mathrm{pH}$ units. Paired with the assumption of normality, this value was used to represent model uncertainty associated with StrPI predictions. These can be seen in Fig. 5, where dashed lines are drawn at \pm 1.0 and \pm 2.0 standard deviations from the mean.

\subsection{Calibration Using Synthetic Results}

The StrPI model was developed specifically to permit field calibration of the generalized StrPI equation. As these calibrations are performed by operators, they can accommodate for plant- or process-specific irregularity and nuance that is not captured by universal models. This calibration factor can be added to Eqs. (30) or (31) to establish a calibrated StrPI, $\operatorname{Str}_{\mathrm{PI}}$ :

$$
S t r P I_{c}=p H-C-10.52+2.363 \sqrt{7.928+0.8464 \log _{10}\left(M g_{T} \cdot N_{T} \cdot P_{T}\right)}
$$

where $p H$ is the measured $\mathrm{pH}$ of the waste stream and $C$, the StrPI calibration factor, corrects for the uniform bias in an uncalibrated model. $C$ is a single number, likely positive, that can be adjusted to allow for a less 
(or more) conservative StrPI. While a least-squares fit of the synthetic experiments estimated that $C=1.16$, this distributes uncertainty equally about the mean-which is not necessarily ideal for use in operations. The model should be recalibrated (i.e. $C$ should be adjusted) to incorporate the specific predictive needs of individual treatment plants. Concentrations are in $\mathrm{mol} / \mathrm{L}$ as $[\mathrm{Mg}],[\mathrm{N}]$ and $[\mathrm{P}]$. Conversely, using concentrations in $\mathrm{mg} / \mathrm{L}$ :

$S t r P I_{c}=p H-C-10.52+2.363 \sqrt{-3.095+0.8464 \log _{10}\left(M g_{m g / L} N_{m g / L} P_{m g / L}\right)}$

Fig. 7 contains the calibrated $\operatorname{Str} P I^{*}$ vs. measured $\mathrm{pH}$ at precipitation for all synthetic precipitation experiments included in the fixed effects model. Calculations of $\operatorname{Str} P I_{c}$ were calculated using a $C$ value of 0.90 in the top subplot and 1.42 in the bottom subplot. These values represent two standard deviations below and above the mean $(C=1.16)$, respectively. The data in Fig. 7 are well represented within \pm 2 standard deviations, where about $95 \%$ of normally distributed data should fall.

\subsection{Calibration-Updated Solubility Product}

A uniform shift in the expected $\mathrm{pH}$ of precipitation to accommodate empirical results is a viable engineering solution to an uncertain situation. The bias corrected by $C$ may be a result of several factors. Those factors can include kinetics, inhomogeneities, or-at least in part-because of an incorrect assumption of $K s p$. Solubility product implications of the model calibration can be examined by comparing the quadratic fit of $p K_{\text {spcond }}$ (Eq. (26)) to a quadratic fit corrected by subtracting $C$. The magnitude of the effects of calibration can be seen in Fig. 8, where the $p K_{\text {spcond }}$ and $K_{\text {spcond }}$ of an uncalibrated model $(C=0)$ are compared to a calibrated model where $C=1.16$.

Uncertainty that results from the wide range of equilibrium constants described in Barnes and Bowers
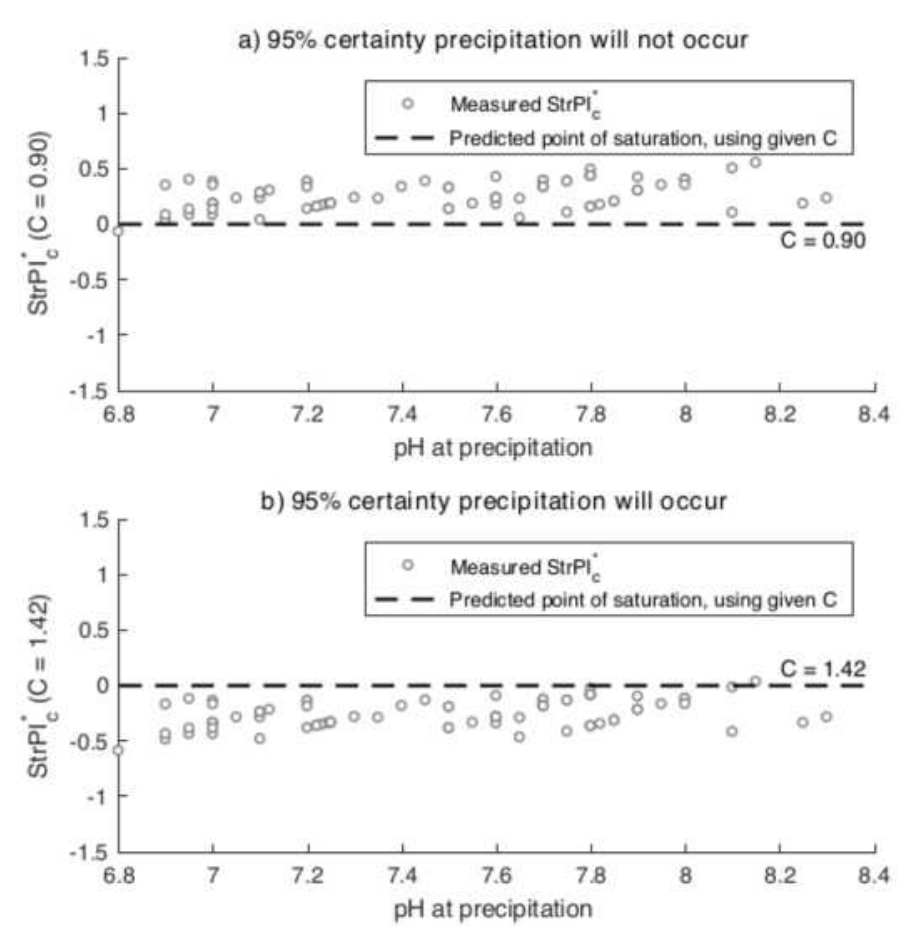

Fig. 7 The calculated $S_{t r P I}$ vs. measured pH of precipitation and associated error for all synthetic struvite precipitation experiments included in the fixed effects model (77 points). For (a), the calibration factor, $C$, is set to 0.90 - two standard deviations below the least-squares estimate of $C$. This calibration was selected so there is $95 \%$ certainty precipitation that will occur when $\operatorname{StrPI}_{c}>0$ (reasonable for preventing precipitation). For (b), $C$ is set to 1.42 - two standard deviations above the least-squares estimate of $C$ (reasonable for facilitating precipitation). Note, many of the data points are coincident or stratified as a result of the identical duplicate pairs and the 0.10 unit resolution of pH measurements. 

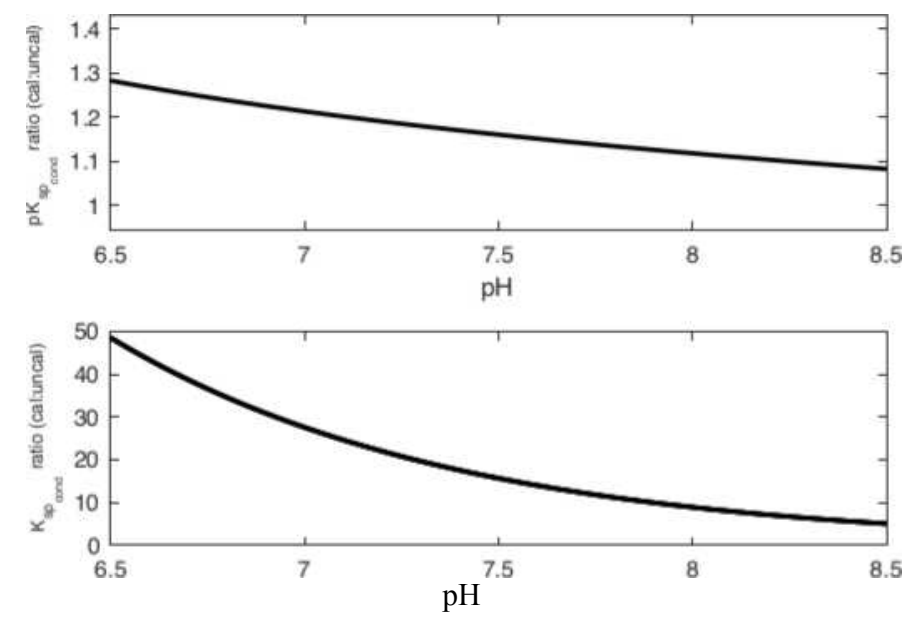

Fig. 8 The ratio of a calibrated StrPI model $(C=1.16)$ to an uncalibrated model $(C=0)$. On the upper subplot, the two $p K_{\text {spcond }}$ values were evaluated using the simplified $p K_{S P c o n d}$ model outlined in Eq. (26) over the pH range of 6.5 to 8.5. This value is converted to the $K_{\text {spcond }}$ on the lower subplot.

[7] may contribute to the uniform bias; however, the published $p K_{s p}$ values at $25^{\circ} \mathrm{C}$ and $I=0$ have a range of about 1 order of magnitude and a mean of 12.96. As such, it is unlikely the large $p K_{\text {spcond }}$ ratios displayed in Fig. 8 are a result of equilibrium constant uncertainty alone, if at all. The overprediction of precipitation is likely in part due to kinetics, and the conditional solubility products presented in Fig. 8 may be markedly different from those derived through comprehensive chemical analysis.

Following the calibration of StrPI to synthetic solutions and the conclusion that it is functionally independent of $G$ and $I$ for practical purposes, the model was verified using real wastewater samples at an operating treatment plant.

\section{Precipitation in Field}

\subsection{Field Results}

Coupons were placed in reactors where struvite scaling could realistically occur. The $\operatorname{Str} P I_{c}$ model $(C=$ $0.90)$ accurately predicted long-term scaling in the field when using measured values (90th percentile of $\mathrm{pH}$, $[\mathrm{Mg}],[\mathrm{P}]$ and $[\mathrm{N}])$ at each coupon location as inputs. This can be seen in Fig. 9, where the 90th percentile is represented by the top of the error bars. The specific choice of 90 percent is unsubstantiated outside of the field data's quality-of-fit; however, it is reasonable to use the worst-case scenario for $\operatorname{Str}_{P} I_{c}$ inputs (e.g. 90th percentiles of measurements) if preventing precipitation is critical. It should be noted, it is unlikely that 90th percentile values of $\mathrm{pH},[\mathrm{Mg}],[\mathrm{P}]$ and $[\mathrm{N}]$ will occur concurrently in a wastewater stream, and the error bars likely enclose well over $99.9 \%$ of potential $S t r P I_{c}$ values. The predictions fit without false negatives or positives when using values one standard deviation above the mean (approx. 66th percentile), but this will vary between treatment facilities. When the $S t r P I_{c}$ is applied to a new treatment process, the distributions of waste stream concentrations should be evaluated to ensure they are not heavily skewed in a way that would undermine predictions. Also, the model should be re-calibrated if precipitation does not occur near a $S t r P I_{c}$ of zero.

As shown in Fig. 9, solutions evaluated using the 90th percentile of measurements never resulted in precipitation when the $\operatorname{StrPI}_{c}$ was less than zero. Further, the same predictions also correctly anticipated struvite buildup on three of five coupons where the calculated $\operatorname{Str} I_{c}$ was greater than, or within, one standard deviation of zero.

\subsection{Suggested Initial Calibration Values}

The StrPI calibration value, $C$, was found to be 1.16 when fit using least-squares regression on the lab data. 


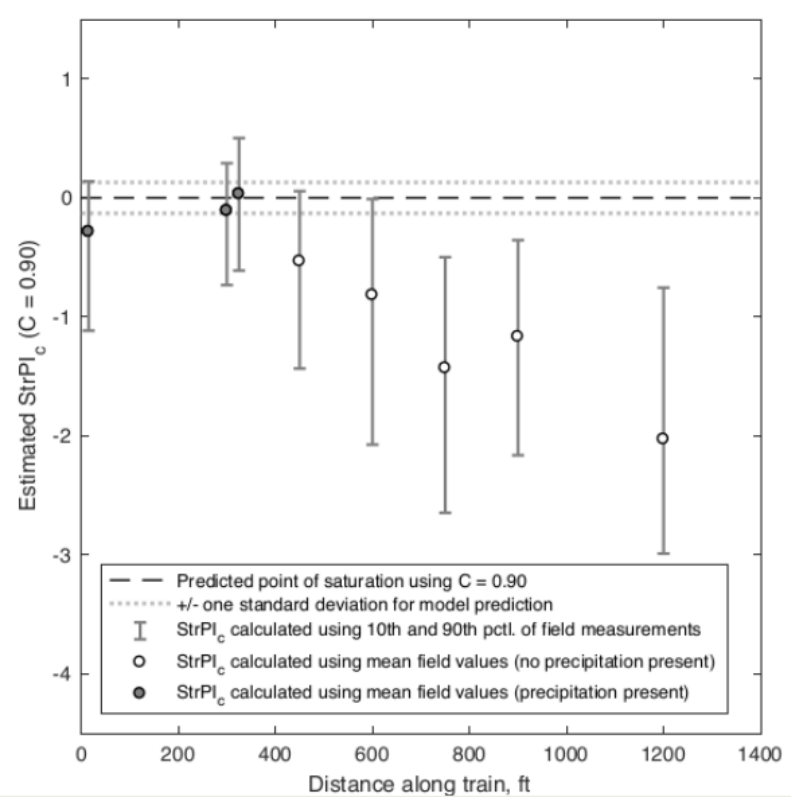

Fig. 9 Field results for eight coupons submerged along a 415-meter (1,360-ft) centrate nitrification basin, each evaluated for the existence of struvite precipitation. Temperature was $25{ }^{\circ} \mathrm{C}\left( \pm 2{ }^{\circ} \mathrm{C}\right)$. The dashed line denotes the expected point of precipitation for the calibrated model $\left(\mathrm{StrPI}_{c}=\mathbf{0}\right)$ using a $\boldsymbol{C}$ of 0.90 (empirical fit from lab experiments). Dotted lines denote a model confidence interval of \pm one standard deviation. The error bars depict the estimated range of the StrPI over the two-week experiment, calculated using 10th and 90th percentile of measured $\mathrm{pH},[\mathrm{Mg}],[\mathrm{P}]$ and $[\mathrm{N}]$ values. Both circular markers represent the $\operatorname{StrPI}_{c}$ evaluated at the mean values of each set of $\mathrm{pH},[\mathrm{Mg}],[\mathrm{P}]$ and $[\mathrm{N}]$.

This calibration, which appears to fit well using the 90th percentile of field measurements, does not take into account the predictive needs of all situations. If a system is designed to precipitate struvite-the Ostara $^{\mathrm{TM}}$ or AirPrex ${ }^{\circledR}$ processes, for example-then ideal calibration would ensure precipitation rather than its absence. Specifically, it might use a $C$ greater than 1.16 to err on the side of underprediction and reduce the prevalence of false positives. Conversely, if a waste stream is highly variable, localized areas are particularly problematic, or minimal struvite precipitation is especially detrimental, a conservative $C$ may be ideal. For example, $C$ could be set so low that an $\operatorname{StrPI}_{c}$ of zero falls several standard deviations above the lab-derived estimation of the saturation point.

The $\operatorname{Str} I_{c}$ model requires that $C$ be set based on localized condition. Its validity, therefore, should be periodically assessed and updated to reflect changing field conditions. Labscale experimentation similar to that laid out in this study can be used to quickly analyze new waste conditions and adjust calibration accordingly. However, situational inhomogeneity and the potential for $\mathrm{CO}_{2}$ evolution require that the primary metric for calibration be the observation of precipitation within actual processes. Precipitation can be evaluated through use of coupons (as discussed in this study), chemical analysis of grab samples, or through the continued telltale accumulation of crystals on mixers, pipes, and other problem areas.

The $C$ value should be set at a point that reflects the safetyfactor (or other predictive needs) of the individual process, and the model should be recalibrated when new data sets become available or aqueous conditions change substantially. Increasing the value of $C$ will make the $S t r P I_{c}$ predictions less conservative (precipitation occurs at a lower $\operatorname{Str} P I_{c}$ ), and vice versa. The initial implementation of $\operatorname{Str}_{\mathrm{P}} I_{c}$ can be simplified through use of these calibration guidelines, drawn from this study's field and laboratory experiments. Using measured $\mathrm{pH},[\mathrm{Mg}],[\mathrm{P}]$ and $[\mathrm{N}]$ data: 
$C=\ldots$

$0 \Rightarrow$ uncalibrated and highly conservative

$0.90 \Rightarrow$ struvite prevention $(95 \%$ certainty of no precipitation when $\operatorname{StrPI}_{c}<0$ )

$1.04 \Rightarrow$ calibrated to 90 th pctl. of field data (lowest $C$ with no false positives)

$1.16 \Rightarrow$ calculated using least squares regression of lab data (centered on error)

$1.42 \Rightarrow$ struvite recovery $(95 \%$ certainty of precipitation when $\left.S \operatorname{trPI} I_{c}>0\right)$

Note: statements of certainty apply to equilibrium model fit, not to the underlying variability of the waste stream. The underlying distributions of measured model inputs and the selection of which percentile to use for said inputs (e.g. 90th percentile) may significantly impact model effectiveness. Future research may look to evaluate the $\operatorname{Str} P I_{c}$ in variable waste conditions using a Monte-Carlo framework, similar to that discussed in Barnes and Bowers [7].

The $\operatorname{StrPI}_{c}$ model is designed to be used as a predictive tool that can be useful for general operational decisions, not as an analytical refinement of existing theory. Model flexibility, therefore, is more important than finding a single, unifying equation. The use of a single additive calibration constant to modulate predictions over a wide $\mathrm{pH}$ range streamlines $\operatorname{Str}_{\mathrm{PI}} \mathrm{c}_{c}$ framework implementation, shortens the learning curve for plant operators, and simplifies in-the-moment calculations.

\section{Conclusions}

The struvite precipitation index is useful for wastewater operations as an accessible metric for evaluating the potential of an aqeuous system to precipitate struvite (either to prevent or promote struvite precipitation). While this effort was restricted to a $\mathrm{pH}$ range of 6.0 to 8.5 , it was shown synthetically to be effective in its predictions. This conclusion was verified through a complex field case.

A calibration constant, $C$, was included in the $\operatorname{Str} P I_{c}$ equation to accommodate plant-specific kinetics, uncertainty, inhomogeneity, and a desired factor of safety. Jar-test results suggest an initial calibration of $C$ $=1.42$ for promoting struvite precipitation and $C=$ 0.90 for preventing it. The $\operatorname{StrPI}_{c}$ is modeled as a function of $[\mathrm{Mg}],[\mathrm{N}]$ and $[\mathrm{P}]$ (each as $\mathrm{mol} / \mathrm{L}$ in Eq. (38) or $\mathrm{mg} / \mathrm{L}$ in Eq. (39)) and solution $\mathrm{pH}$. The approach was verified in a field case, and $\operatorname{StrPI}_{c}$ predictions were found to fit best when using the 90th percentile values of concentrations derived from distributions of waste stream measurements.

It is possible to adapt the StrPI equation to processes that are highly dissimilar to those tested in this study. Refinements could accommodate abnormal pH levels, ionic strengths, and turbulence; significant localized $\mathrm{pH}$ spikes due to carbonate evolution; or extreme differences between $[\mathrm{Mg}],[\mathrm{N}]$ and $[\mathrm{P}]$. As presented, however, the StrPI equation can serve as a valuable tool for municipal wastewater treatment plants subject to struvite scaling or performing nutrient reclamation. Process-specific calibration allows a user to account for stream uncertainty and variability in a flexible and robust manner. Lastly, the StrPI can be a useful tool to predict the potential effects of constituent spikes, upstream $\mathrm{pH}$ modulation, or other significant changes in plant operations. Currently, these conditions can only be assessed after precipitation has occurred or through the use of highly conservative computer models.

\section{Acknowledgements}

This research was supported by a grant from Premier Magnesia, LLC.

Assisted in the lab by J. M. Darville and N. M. Monteiro.

\section{References}

[1] Ohlinger, K. N., Young, T. M., and Schroeder, E. D. 1998. "Predicting Struvite Formation in Digestion." Water Research 32 (12): 3607-14.

[2] Mamais, D., Pitt, P. A., Cheng, Y. W., Loiacono, J., and Jenkins, D. 1994. "Determination of Ferric Chloride Dose to Control Struvite Precipitation in Anaerobic Sludge Digesters." Water Env. Research 66 (7): 912-8. 
[3] Horenstein, B. K., Hernandez, G. L., Rasberry, G., and Crosse, J. 1990. "Successful Dewatering Experience at Hyperion Wastewater Treatment plant." Water Sci. Technology 22 (12): 183-91.

[4] Benisch, M., Clark, C., Sprick, R., and Baur, R. 2000. "Struvite Deposits: A Common and Costly Nuisance." WEF Operations Forum.

[5] Melia, P., Cundy, A., Sohi, S., Hooda, P., and Busquets, R. 2017. "Trends in the Recovery of Phosphorus in Bioavailable Forms from Wastewater." Chemosphere 186: 381-95.

[6] Ye, Y., Ngo, H. H., Guo, W., Lie, Y., Li, J., Liu, Y., Zhang, X., and Jia, H. 2017. "Insight into Chemical Phosphate Recovery from Municipal Wastewater." Sci. of the Total Env. 576: 159-71.

[7] Barnes, N. J., and Bowers, A. R. 2017. "A Probabilistic Approach to Modeling Struvite Precipitation with Uncertain Equilibrium Parameters.." Chem. Eng. Sci. 161: 178-86.

[8] Metcalf \& Eddy Inc., Tchobanoglous, G., Tsuchihashi, R., and Burton, F. L. 2013. Wastewater Engineering: Treatment and Resource Recovery, 5th ed. New York: McGraw-Hill Education.

[9] Doyle, J. D., and Parsons, S. A. 2002. "Struvite Formation, Control and Recovery." Water Research 36: 3925-40.

[10] Bouropoulos, N. C., and Koutsoukos, P. G. 2000. "Spontaneous Precipitation of Struvite from Aqueous Solutions." J. Crystal Growth 213: 381-8.

[11] Stumm, W., and Morgan, J. J. 1970. Aquatic Chemistry. New York: John Wiley and Sons.

[12] Snoeyink, V. L., and Jenkins, D. 1980. Water Chemistry. New York: John Wiley and Sons.

[13] Ali, I., and Schneider, P. A. 2008. "An Approach of Estimating Struvite Growth Kinetic Incorporating Thermodynamic and Solution Chemistry, Kinetic and Process Description.” Chemical Eng. Sci. 63: 3514-25.

[14] Musvoto, E. V., Wentzel, M. C., and Ekama, G. A. 2000. "Integrated Chemicalphysical Process Modelling I. Development of a Kinetic Based Model for Weak Acid/Base Systems..” Water Research 34: 1857-80.

[15] Ohiinger, K. N., Young, T. M., and Schroeder, E. D. 2000. "Post Digestion Struvite Precipitation Using a Fluidized Bed Reactor.” J. Env. Eng. 126: 361-8.
[16] Aage, H. K., Andersen, B. L., Blom, A., and Jensen, I. 1997. "The Solubility of Struvite." J. Radioanal. Nucl. Chem. 223 (1-2): 213-5.

[17] Hanhoun, M., Montastruc, L., Azzaro-Pantel, C., Biscans, B., Frche, M., and Pibouleau, L. 2011. "Temperature Impact Assessment on Struvite Solubility Product: A Thermodynamic Modeling Approach." Chem. Eng. J. 167: 50-8.

[18] Bhuiyan, M. I. H., Mavinic, D. S., and Beckie, R. D. 2007. "A Solubility and Thermodynamic Study of Struvite.” Env. Technology 28 (9): 1015-26.

[19] IUPAC 2011. Stability Constants Database. Academic Software and the Royal Society of Chemistry.

[20] Elimelech, M., Jia, X., Gregory, J., and Williams, Richard 1998. Particle Deposition and Aggregation: Measurement, Modelling and Simulation (Colloid and Surface Engineering), 1st ed. Butterworth-Heinemann,.

[21] Weber, W., and DiGiano, F. 1996. Process Dynamics in Environmental Systems, $1 \mathrm{st}$ ed. Hoboken, NJ: Wiley-Interscience.

[22] Bridgewater, L., Association, American Public Health, Association, American Water Works, and Federation, Water Environment. 2012. Standard Methods for the Examination of Water and Wastewater, 22nd ed. Washington, D.C.: American Public Health Association.

[23] Sposito, G. 2008. The Chemistry of Soils, 2nd ed. Oxford: Oxford University Press.

[24] Ancheyta, J. 2017. Chemical Reaction Kinetics: Concepts, Methods and Case Studies. New York: John Wiley and Sons Inc..

[25] Ang, A., and Tang, W. 2007. Probability Concepts in Engineering-Emphasis on Applications in Civil and Environmental Engineering. New York: John Wiley \& Sons, Inc., 406.

[26] Das, D., Keinath, T. M., Parker, D. S., and Walhberg, E. J. 1993. "Floc Breakup in Activated Sludge Plants." Water Env. Research 65: 138-45.

[27] Parker, D. S., Kaufman, W. J., and Jenkins, D. 1971. "Physical Conditioning of Activated sludge Floc." $J$. Water Pollution Control Fed. 43: 1817.

[28] Walpole, R., Myers, R., Myers, S., and Ye, K. 2002. Probability and Statistics for Engineers and Scientists, 7th ed. Upper Saddle River, NJ: Prentice Hall, 730. 